\title{
Electrocatalysts for the Selective Reduction of Carbon Dioxide to Useful Products
}

\author{
Dan Ren, Yun Huang, and Boon Siang Yeo*
}

\begin{abstract}
The electrochemical reduction of carbon dioxide $\left(\mathrm{CO}_{2}\right)$ to hydrocarbons and alcohols holds great promise as a sustainable and green method to produce valuable carbon fuels. In this work, we review the catalysts used in the selective reduction of $\mathrm{CO}_{2}$ to formate, carbon monoxide, methane and ethylene.
\end{abstract}

Keywords: Carbon dioxide $\cdot$ Electrocatalysis $\cdot$ Mechanism $\cdot$ Selectivity

\section{Introduction}

Currently, more than $80 \%$ of the world's energy needs are met by burning fossil fuels such as oil or natural gas. The supply of these fuels is intrinsically limited and will eventually run out. Combustion of fossil fuels also generates carbon dioxide $\left(\mathrm{CO}_{2}\right)$, which is a suspected accelerant of global warming and a regulatory burden for industrial emitters..$^{[1]}$ One solution for reducing atmospheric $\mathrm{CO}_{2}$ is carbon capture and sequestration. ${ }^{[2]}$ The practicality of this process is however constrained by safety, space and cost. The alternative is to chemically reduce the emitted $\mathrm{CO}_{2}$ into carboxylic acids, hydrocarbons or alcohols. The advantage of this approach is that some of these products (for example, methane) are already part of our energy infrastructure. Hence, our existing fossil fuels-powered machines do not need to be modified extensively. Hydrocarbon and alcohol fuels, especially if they are liquids, are also more easily stored and transported. If the energy used for the reduction processes is generated from a renewable source such as solar or wind, we could envisage a future fuel production cycle that is closed-loop with net zero carbon emission. $\mathrm{CO}_{2}$ can also be used as a cheap carbon source for synthesizing bigger organic molecules such as ethylene, which is a valuable chemical feedstock for the polymer industries.

$\mathrm{CO}_{2}$ reduction can be achieved photocatalytically and electrochemically. Photocatalytic reduction of $\mathrm{CO}_{2}$ is more

\footnotetext{
${ }^{\star}$ Correspondence: Dr. B. S. Yeo Department of Chemistry

Faculty of Science

National University of Singapore

3 Science Drive 3, Singapore 117543

Tel.: +65 65162836

E-mail: chmyeos@nus.edu.sg
}

direct, but the conversion, as measured by the quantum yield, is very low. ${ }^{[3]}$ The electrochemical reduction of $\mathrm{CO}_{2}$ proceeds more efficaciously, with faradaic efficiencies up to 80-90\% under certain conditions. ${ }^{4]}$ Considering that the electricity applied for the process can be generated from solar farms and that its price is fast approaching grid parity, an arguably more promising way of converting $\mathrm{CO}_{2}$ to hydrocarbons and alcohols would be by electrochemical methods.

The electrochemical reduction of $\mathrm{CO}_{2}$ has been explored using heterogeneous and molecular catalysts under a variety of conditions such as different working potentials and in aqueous, organic and ionic liquids. ${ }^{[4,5]} \mathrm{CO}_{2}$ electroreduction using metal electrodes in aqueous electrolytes has been most extensively studied, especially by Y. Hori and co-workers. ${ }^{[6]}$ The metals tested for $\mathrm{CO}_{2}$ electroreduction have been traditionally divided into four categories. The first, which consists of metals such as $\mathrm{Pb}, \mathrm{Cd}, \mathrm{Sn}$ and $\mathrm{Hg}$, mainly reduces $\mathrm{CO}_{2}$ to $* \mathrm{OCHO}$ or $* \mathrm{COOH}$, which then undergoes a net one-electron transfer to become formate $\left(\mathrm{HCOO}^{-}\right)$. Metals in the second group ( $\mathrm{Au}, \mathrm{Ag}, \mathrm{Zn}$ ) have the capability to dissociate $* \mathrm{COOH}$, via a single $\mathrm{C}-\mathrm{O}$ bond scission to give $\mathrm{CO}$, which is liberated from the surface as a gas. The third category of metals ( $\mathrm{Ni}, \mathrm{Fe}, \mathrm{Pt}, \mathrm{Ti})$ does not sustainably reduce $\mathrm{CO}_{2}$. Hydrogen is formed instead. This is likely due to the initial formation of strongly adsorbed $\mathrm{CO}$ on the surface, which acts as a poison to inhibit any further $\mathrm{CO}_{2}$ reduction. Finally, the fourth group which consists of copper metal is known to hydrogenate and even dimerize $\mathrm{CO}_{2}$ into substantial amounts of hydrocarbons and alcohols. ${ }^{[5 a]}$ To date, copper and its derivatives are the most promising catalysts for reducing $\mathrm{CO}_{2}$ to methane, ethylene and ethanol, etc.
However, problems such as poor selectivity and the need for high overpotentials prevent this process from being commercialized. Jaramillo and co-workers detected at least 16 different products during $\mathrm{CO}_{2}$ electroreduction on a polycrystalline copper surface (Fig. 1). ${ }^{[5 e]}$ The poor selectivity could be attributed to the variety of reaction sites on the surface and the fact that $\mathrm{CO}_{2}$ electroreduction on copper is a multistep process with many shared intermediates and reaction pathways. ${ }^{[7]}$ The selectivity of reaction is also highly susceptible to changes in local $\mathrm{pH}$, temperature and types of electrolytes used. ${ }^{[4,8]}$ Bond breaking and formation further impose significant kinetic barriers which account for the sizable overpotential needed. Fast deactivation of the $\mathrm{Cu}$ catalyst is another serious issue, and usually occurs after several hours of $\mathrm{CO}_{2}$ reduction. [9] The loss of activity for $\mathrm{CO}_{2}^{2}$ reduction is believed to originate from amorphous carbon and/ or heavy metals deposition on the surface during $\mathrm{CO}_{2}$ reduction.

In the light of the above considerations, recent works performed in the field of $\mathrm{CO}_{2}$ electroreduction have focused on the development of robust catalytic systems that have high selectivity towards a certain product at a minimal overpotential. Work has been done to correlate the product distribution with factors such as morphology and chemical composition of the electrodes, $\mathrm{CO}_{2}$ pressure, reaction temperature and buffer strength/type. ${ }^{[4,5 f, 8 b, 10]}$ Quantum chemical simulations using density functional theory have also been utilized to analyze the underlying mechanism of $\mathrm{CO}_{2}$ electroreduction. ${ }^{[7,11]}$ Although these computational models simplify the reaction environment, they nonetheless provide an excellent guide for designing electrocatalysts.

A review summarizing some advances 


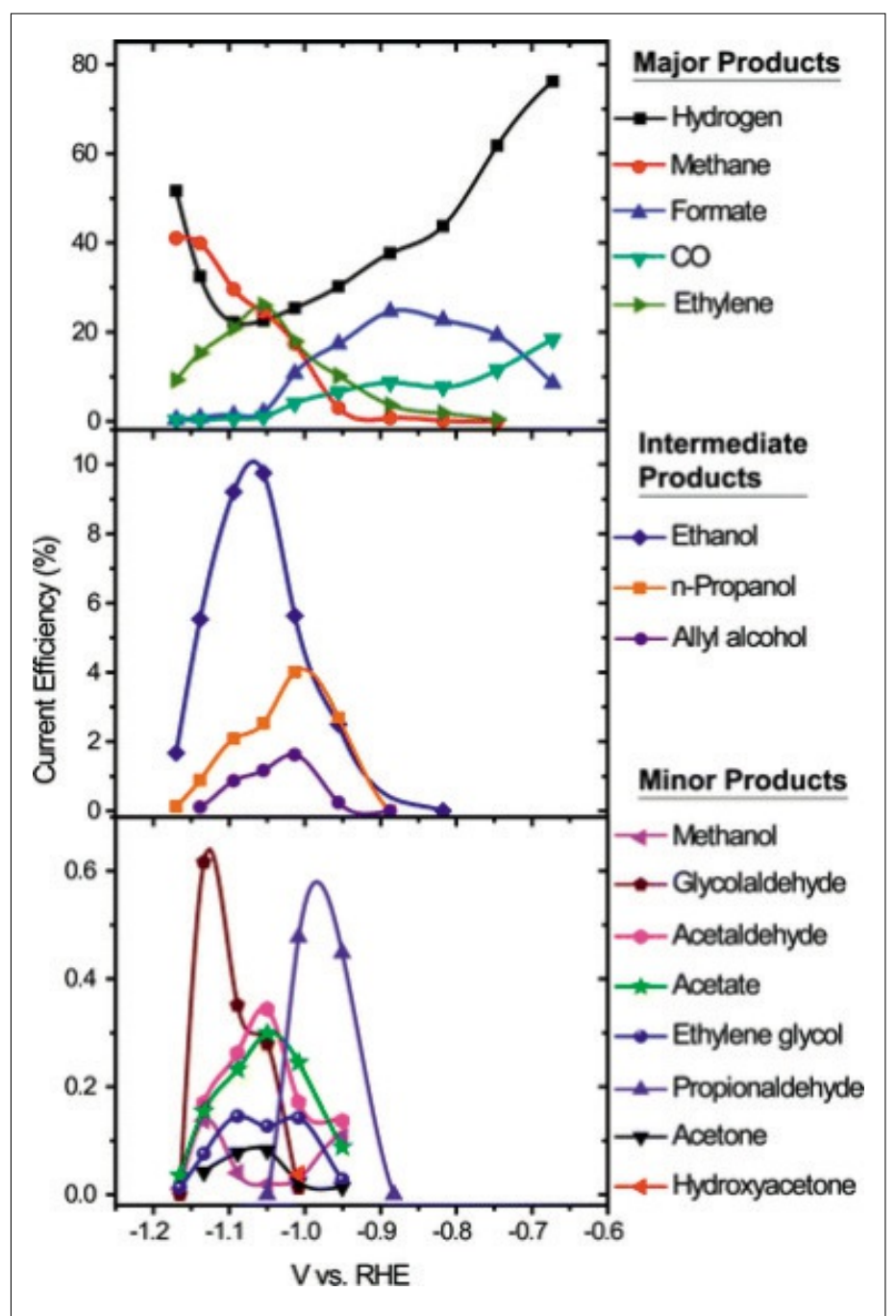

Fig. 1. Faradaic efficiencies for $\mathrm{CO}_{2}$ electroreduction products formed on polycrystalline copper as a function of potential. Reprinted with permission from ref. [5e]. Copyright (C) Royal Society of Chemistry.

made in the selective electroreduction of $\mathrm{CO}_{2}$ to formate, $\mathrm{CO}, \mathrm{CH}_{4}$ and $\mathrm{C}_{2} \mathrm{H}_{4}$ will be presented. Electrocatalysts consisting of metals, metal oxides and metallic nanostructures, will be grouped according to their selective electroreduction of $\mathrm{CO}_{2}$ to one particular product. The intention of this review is not to summarize all the works on $\mathrm{CO}_{2}$ electroreduction. We therefore apologize for some unavoidable omissions. More comprehensive reviews of $\mathrm{CO}_{2}$ electroreduction can be found in the works of Gattrell et al., Hori et al. and Lu et al. ${ }^{[8 \mathrm{a}, 12 \mathrm{a}, \mathrm{b}]}$

\section{Catalysts for Selective $\mathrm{CO}_{2}$ Reduction}

\subsection{Formate}

The electrochemical half reaction for the formation of formate $\left(\mathrm{HCOO}^{-}\right)$is:

$$
\begin{aligned}
& \mathrm{CO}_{2}+\mathrm{H}^{+}+2 \mathrm{e}^{-}=\mathrm{HCOO}^{-} \\
& \left(\mathrm{E}_{0}=-0.225 \mathrm{~V} \text { vs RHE }\right)^{[8 \mathrm{a}]}
\end{aligned}
$$

It is widely accepted that $\mathrm{CO}_{2}$ undergoes proton and electron transfer to give either $* \mathrm{COOH}$ or $* \mathrm{OCHO}$. The intermediate then desorbs as formate after a net one-electron transfer. ${ }^{[11 \mathrm{a}, 13]}$

Hori et al. studied the electrochemical reduction of $\mathrm{CO}_{2}$ at different metal electrodes and found that formate is selectively produced on $\mathrm{Pb}, \mathrm{Hg}$, In, $\mathrm{Sn}, \mathrm{Cd}$ and $\mathrm{Tl}$ in $0.1 \mathrm{M} \mathrm{KHCO}_{3} \cdot{ }^{[6]}$ The faradaic efficiencies range from 78.4 to $99.5 \%$, and the overpotentials required under the tested current density range from 0.85 to $1 \mathrm{~V}$. On Pb metal, Köleli et al. reported $90 \%$ faradaic efficiency of formate production in $0.5 \mathrm{M} \mathrm{KHCO}_{3}$ with an overpotential of $\sim 0.6 \mathrm{~V}$ in an electrochemical fixed bed reactor. ${ }^{[14]}$ Metal oxides have also been explored for $\mathrm{CO}_{2}$ reduction to formate. $\mathrm{Wu}$ et al. studied the relationship between the thickness of tin oxide layers and catalytic performance. ${ }^{[15]}$ The formation of formate was optimized using a $3.5 \mathrm{~nm}$ thick $\mathrm{SnO}_{\mathrm{x}}$ layer, with a faradaic efficiency of $64 \%$ at an overpotential of $\sim 0.4 \mathrm{~V}$. Zhang et al. synthesized tin oxide nanocrystals with high surface areas. ${ }^{[16]}$ This catalyst can produce formate at overpotentials as low as $0.34 \mathrm{~V}$. When supported on graphene, the faradaic efficiency of formate can reach $>93 \%$ at an overpotential of $1.1 \mathrm{~V}$. $5 \mathrm{~nm}$-sized tin oxide particles were also found to give the best performance. This was attributed to the optimal balance between its surface- $\mathrm{CO}_{2}{ }^{-}$intermediate interaction and kinetic activation towards protonation and further reduction. Copper rubeanate metal organic frameworks (CRMOF) was also recently found to be more efficient and selective than $\mathrm{Cu}$ metal in producing $\mathrm{HCOO}^{-}$from $\mathrm{CO}_{2}$ reduction. [17] The onset potential for $\mathrm{CO}_{2}$ reduction on CR-MOF was $0.2 \mathrm{~V}$ more positive compared to that on a $\mathrm{Cu}$ metal electrode. Furthermore, the quantity of formate was 13 times larger. The metallic site of CRMOF is ionic, which is thought to decrease the electron density of $\mathrm{Cu}$. This may lead to weaker adsorption of $\mathrm{CO}_{2}$ which prevents it from being further reduced, thus giving a higher yield of $\mathrm{HCOO}^{-}$.

\subsection{Carbon Monoxide}

The electrochemical half reaction for the formation of carbon monoxide is:

$$
\begin{aligned}
& \mathrm{CO}_{2}+2 \mathrm{e}^{-}+2 \mathrm{H}^{+}=\mathrm{CO}+\mathrm{H}_{2} \mathrm{O} \\
& \left(\mathrm{E}_{0}=-0.103 \mathrm{~V} \text { vs } \mathrm{RHE}\right)^{[8 \mathrm{a}]}
\end{aligned}
$$

A moderately adsorbed $* \mathrm{COOH}$ can undergo a single $\mathrm{C}-\mathrm{O}$ bond scission and protonation to give $* \mathrm{CO}$ and $\mathrm{H}_{2} \mathrm{O}$. Weaklybonded *CO can then desorb as a gas. ${ }^{[6]}$ The faradaic efficiencies of $\mathrm{CO}$ production during a constant current electrolysis at $-5 \mathrm{~mA} / \mathrm{cm}^{2}$ on $\mathrm{Au}, \mathrm{Ag}$ and $\mathrm{Zn}$ in $0.1 \mathrm{M}$ $\mathrm{KHCO}_{3}$ electrolyte were 87.1, 81.5, 79.4\% respectively, while the corresponding potentials were at $-1.14 \mathrm{~V},-1.37 \mathrm{~V},-1.54 \mathrm{~V}$ vs. NHE. ${ }^{[6]}$ The overpotentials for these three metal electrodes to produce $\mathrm{CO}$ are therefore $0.6 \mathrm{~V}, 0.9 \mathrm{~V}$ and $1.0 \mathrm{~V}$ respectively. ${ }^{[6]}$ Recently, Kanan and co-workers reported three electrocatalysts that selectively produce $\mathrm{CO}$ at very low overpotentials. ${ }^{[18]}$ They first reported $>50 \%$ $\mathrm{CO}$ production in $\mathrm{CO}_{2}$-saturated $0.5 \mathrm{M}$ $\mathrm{NaHCO}_{3}$ electrolyte on $\mathrm{Sn} / \mathrm{SnO}$ thin films electrodes at an overpotential of $0.6 \mathrm{~V} \cdot{ }^{[18 a]}$ Subsequently, they reported that annealed thick $\mathrm{Cu}_{2} \mathrm{O}$ film exhibited $47 \% \mathrm{CO}$ production in $0.5 \mathrm{M} \mathrm{NaHCO}_{3}$ with an overpotential of $0.25 \mathrm{~V}$, which is much lower than their $\mathrm{Sn} / \mathrm{SnO}_{\mathrm{x}}$ thin films. ${ }^{[18 \mathrm{~b}]}$ Oxidederived $\mathrm{Au}$ nanoparticles, reported by the same group, also exhibit enhanced $\mathrm{CO}$ production with faradaic efficiency of $65 \%$ at $-0.25 \mathrm{~V}$ vs RHE and $96 \%$ at $-0.35 \mathrm{~V}$ vs RHE. The overpotentials are therefore respectively 0.15 and $0.25 \mathrm{~V}^{[18 \mathrm{c}]}$ All three catalysts are essentially metal oxides that have been reduced to their corresponding metals during the application of cathodic potentials. It was hypothesized that unique surface structures produced during the reduction reaction stabilized the formation of $\mathrm{CO}_{2}{ }^{--}$intermediates. This in turn 
lowers the overpotentials required for the formation for CO. A clear description of the nature of these catalytic sites by nanospectroscopy or microscopy would aid in further improvements of these catalysts.

Lu et al. recently reported a dealloyed process to produce nanoporous Ag (npAg) with a unique monolithic and curved inner structure (Fig. 2A). This catalyst exhibited excellent $\mathrm{CO}_{2}$ electroreduction to $\mathrm{CO}$ with a faradaic efficiency of $79 \%$ at $-0.4 \mathrm{~V}$ vs RHE and $90 \%$ at $-0.5 \mathrm{~V}$ vs RHE in $0.5 \mathrm{M} \mathrm{KHCO}_{3}$ (Fig. 2B-D). ${ }^{[19]}$ This exceptional activity could be attributed to the highly curved surface of the np-Ag catalyst which may contain a high density of step sites and higher-index facets. These features could improve the surface migration of the hydrogen donor $\mathrm{HCO}_{3}^{-}$to the surface sites in the interior of the $\mathrm{np}-\mathrm{Ag}$, which is considered to be rate-determining by the authors.

\subsection{Methane and Ethylene}

The electrochemical half reactions for the formation of methane $\left(\mathrm{CH}_{4}\right)$ and ethylene $\left(\mathrm{C}_{2} \mathrm{H}_{4}\right)$ are:

$$
\begin{aligned}
& \mathrm{CO}_{2}+8 \mathrm{e}^{-}+8 \mathrm{H}^{+}=\mathrm{CH}_{4}+2 \mathrm{H}_{2} \mathrm{O} \\
& \left(\mathrm{E}_{0}=0.169 \mathrm{~V} \text { vs RHE }\right)
\end{aligned}
$$

$$
2 \mathrm{CO}_{2}+12 \mathrm{e}^{-}+12 \mathrm{H}^{+}=\mathrm{C}_{2} \mathrm{H}_{4}+4 \mathrm{H}_{2} \mathrm{O}
$$$$
\left(\mathrm{E}_{0}=0.079 \mathrm{~V} \text { vs RHE }\right)^{[8 a]}
$$

$\mathrm{CO}_{2}$ electroeduction to these two products transpire on polycrystalline $\mathrm{Cu}$ surfaces, albeit with the simultaneous production of many other compounds like $\mathrm{HCOO}^{-}$, $\mathrm{CO}, \mathrm{C}_{2} \mathrm{H}_{5} \mathrm{OH}$, etc. (Fig. 1).[4,5e] The poor selectivity can be attributed to the heterogeneity of catalytic sites on the polycrystalline $\mathrm{Cu}$. A highly impactful work to tune the selectivity of $\mathrm{CH}_{4}$ and $\mathrm{C}_{2} \mathrm{H}_{4}$ was first performed by Hori and co-workers. ${ }^{[20]}$ They studied the distribution of products formed on copper single crystals surfaces during $\mathrm{CO}_{2}$ electroreduction at $-5 \mathrm{~mA} /$ $\mathrm{cm}^{2}$ in $0.1 \mathrm{M} \mathrm{KHCO}^{2}{ }^{[20 \mathrm{~b}]} \mathrm{Cu}(111)$ and $\mathrm{Cu}(100)$ were respectively found to be more selective for $\mathrm{CH}_{4}$ and $\mathrm{C}_{2} \mathrm{H}_{4}$ formation. Interestingly, the selectivity could be tuned by introducing atomic steps on these surfaces (brought about by cleaving the single crystal substrates at specific angles). As an illustration, $\mathrm{CO}_{2}$ reduction on $\mathrm{Cu}(100)$ produced $\mathrm{C}_{2} \mathrm{H}_{4}$ and $\mathrm{CH}_{4}$ with faradaic efficiencies of 40.4 and $30.4 \%$ respectively, thus giving a $\mathrm{C}_{2} \mathrm{H}_{4} / \mathrm{CH}_{4}$ ratio of 1.3. The selectivity towards $\mathrm{C}_{2} \mathrm{H}_{4}$ could be enhanced by using a $\mathrm{Cu}(711)$ surface which consisted of four atomic rows of (100) terrace and one atomic height of (111) steps. This catalyst reduced $\mathrm{CO}_{2}$ with fara-
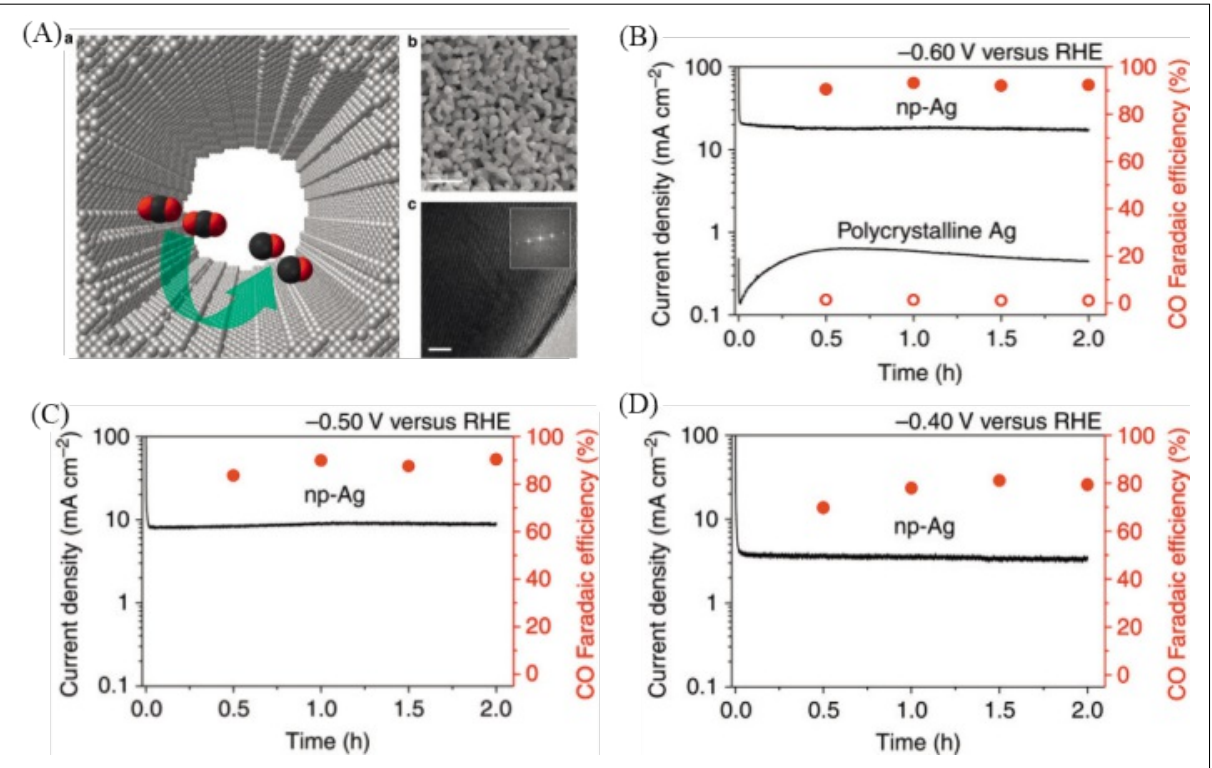

Fig. 2. (A) (a) Schematic diagram of the interior of a nanoporous Ag (np-Ag) catalyst, (b) SEM image of $\mathrm{np}$-Ag dealloyed in $5 \mathrm{wt} \% \mathrm{HCl}$ for $15 \mathrm{~min}$ and further in $1 \mathrm{wt} \% \mathrm{HCl}$ for $30 \mathrm{~min}$ (b, scale bar, $500 \mathrm{~nm}$ ) and (c) corresponding HR-TEM image (scale bar, $2 \mathrm{~nm}$ ). $\mathrm{CO}_{2}$ electroreduction activity of $\mathrm{np}-\mathrm{Ag}$ and polycrystalline silver at (B) $-0.60 \mathrm{~V}$, (C) $-0.50 \mathrm{~V}$ and (D) $-0.40 \mathrm{~V}$ vs. RHE. Adapted with permission from ref. [19]. Copyright (C) Nature Publisher Group.

daic efficiencies of $50.0 \% \mathrm{C}_{2} \mathrm{H}_{4}$ and $5.0 \%$ $\mathrm{CH}_{4}{ }^{.20 \mathrm{a}]} \mathrm{A}$ much higher $\mathrm{C}_{2} \mathrm{H}_{4} / \mathrm{CH}_{4}$ ratio of 10 was thus achieved! A 'volcano'-like plot was also obtained when the $\mathrm{C}_{2} \mathrm{H}_{4} / \mathrm{CH}_{4}$ ratio was plotted against the angle of the crystal orientation with reference to $\mathrm{Cu}(100)$ (Fig. 3). This trend suggests that an optimum density of atomic steps on the terraces is an important factor in enhancing the formation of $\mathrm{C}_{2} \mathrm{H}_{4}$ during $\mathrm{CO}_{2}$ reduction.

Roughened $\mathrm{Cu}$ surfaces have also been found to exhibit enhanced selectivity towards $\mathrm{C}_{2} \mathrm{H}_{4}$ formation. Tang et al. reported that a $\mathrm{Cu}$ surface deposited with roughened $\mathrm{Cu}$ nanoparticles reduced $\mathrm{CO}_{2}$ at $-1.1 \mathrm{~V}$ vs RHE in $0.1 \mathrm{M} \mathrm{KClO}$ electrolyte with faradaic efficiencies of 36 and $\sim 1 \%$ for $\mathrm{C}_{2} \mathrm{H}_{4}$ and $\mathrm{CH}_{4}$ respectively (Fig. 4). ${ }^{[5 f]}$ The selectivity towards ethylene is considerably higher compared to that observed on electrochemically polished and Argon ions $\left(\mathrm{Ar}^{+}\right)$sputtered $\mathrm{Cu}$ surfaces. With the assistance of quantum chemical simulations, it was proposed that a greater surface population of undercoordinated sites on the $\mathrm{Cu}$ nanoparticles would favor the buildup of a high coverage of $\mathrm{HO}^{*}$ intermediates. This would in turn favor the formation rate of $\mathrm{C}_{2} \mathrm{H}_{4}$.

Inspired by these studies, our group prepared $\mathrm{Cu}$ mesocrystal catalysts by the in situ reduction of a $\mathrm{CuCl}$ film during $\mathrm{CO}_{2}$ reduction. ${ }^{[21]}$ This material was shown to reduce $\mathrm{CO}_{2}$ at $-0.99 \mathrm{~V}$ vs RHE to produce $\mathrm{C}_{2} \mathrm{H}_{4}$ and $\mathrm{CH}_{4}$ at faradaic efficiencies of 27.2 and $1.47 \%$ respectively. A

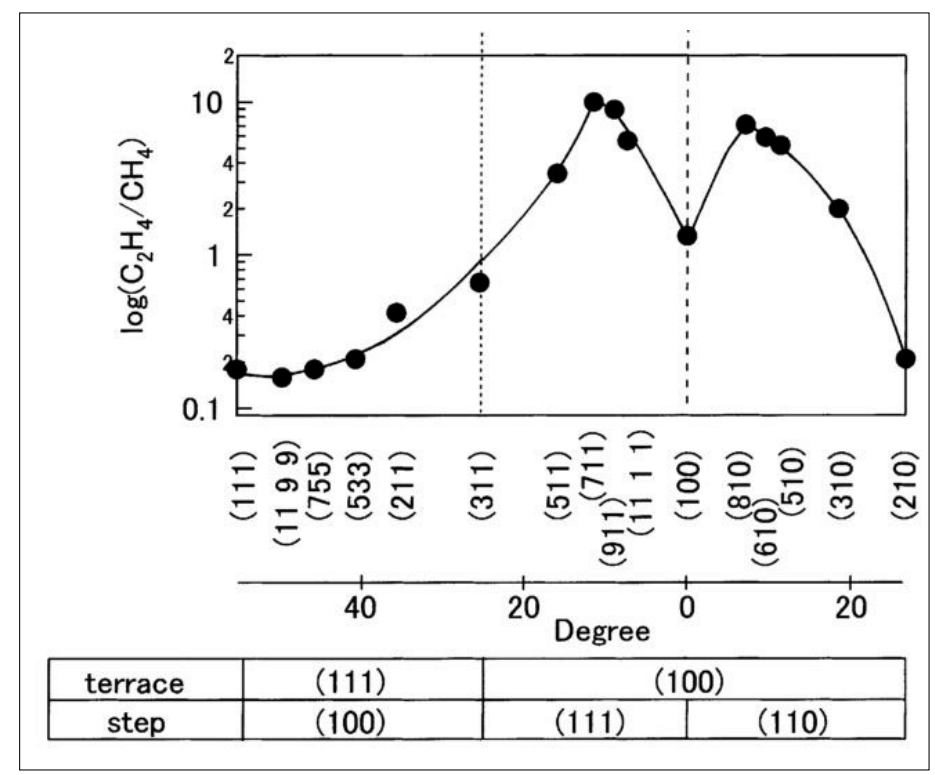

Fig. 3. Plot of log $\left(\mathrm{C}_{2} \mathrm{H}_{4} / \mathrm{CH}_{4}\right)$ value vs. the angle of Cu crystal orientation. The figure is separated into three parts by two dash lines. Left: (111) terrace plus (100) steps; Middle: (100) terrace plus (111) steps; Right: (100) terrace plus (110) steps. Reprinted with permission from ref. [20a]. Copyright (C) Elsevier. 


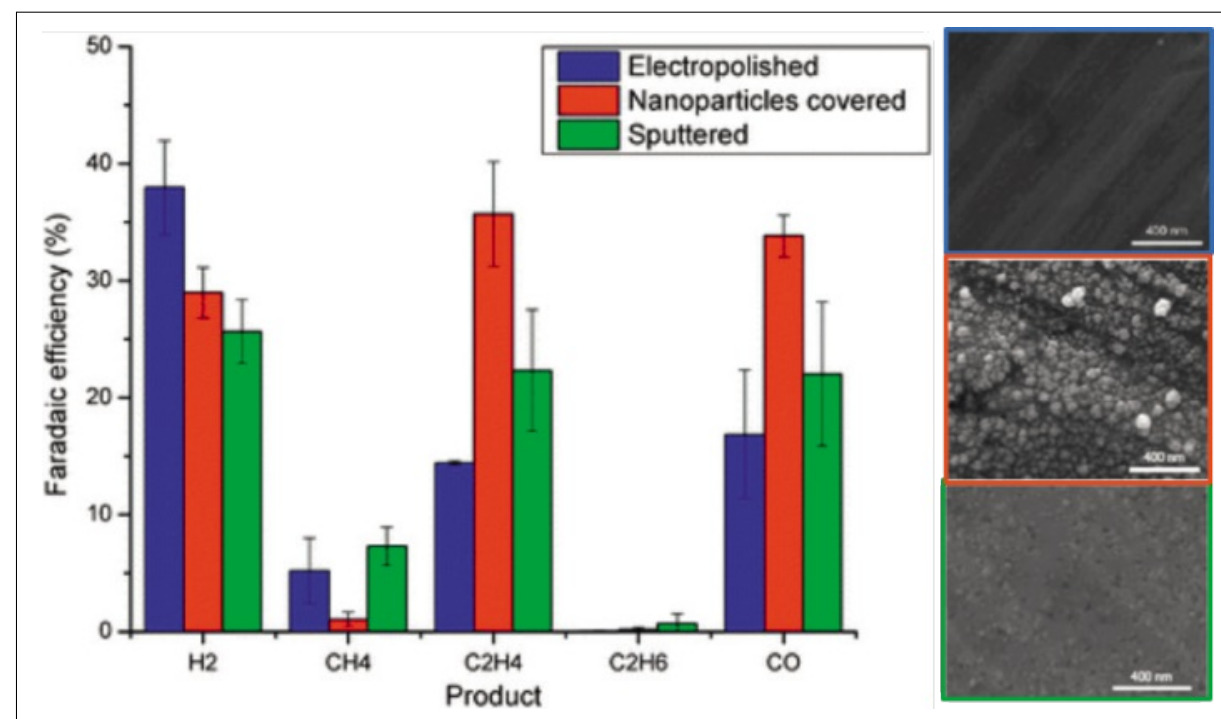

Fig. 4. Faradaic efficiencies for $\mathrm{CO}_{2}$ electroreduction products on three catalyst surfaces in $\mathrm{CO}_{2}-$ saturated $0.1 \mathrm{M} \mathrm{KClO}_{4}$ at $-1.1 \mathrm{~V}$ vs $\mathrm{RHE}$. These are electropolished $\mathrm{Cu}$ surface (in blue), copper nanoparticles covered surface (in red) and sputtered surface (in green). SEM images of the three catalysts are shown on the right hand side. Reprinted from ref. [5f]. Copyright ( ) Royal Society of Chemistry.

$\mathrm{C}_{2} \mathrm{H}_{4} / \mathrm{CH}_{4}$ ratio of $\sim 18$ was thus achieved (Fig. 5). In contrast, an electropolished $\mathrm{Cu}$ surface and $\mathrm{Cu}$ nanoparticles formed by pulse electrodeposition exhibited $\mathrm{C}_{2} \mathrm{H}_{4} / \mathrm{CH}_{4}$ ratios of only 3.1 and 2.3 respectively. The formation and characterization of the $\mathrm{Cu}$ mesocrystals is shown in Fig. 6. $\mathrm{CuCl}$ was first electrodeposited on a pristine $\mathrm{Cu}$ electrode (Fig. 6A,B). X-ray diffraction (XRD) and X-ray photoelectron spectroscopy (XPS) demonstrated the presence of $\mathrm{CuCl}$ (Fig. 6C,D). Then, the sample was used as catalyst for $\mathrm{CO}_{2}$ reduction. Within a few hundred seconds into the reduction process, well-defined cuboids decorated with numerous particles were observed (Fig. 6E-H). These, termed by us as $\mathrm{Cu}$ mesocrystals, were confirmed by XRD and XPS to be metallic Cu. Highresolution transmission electron microscopy (HRTEM) revealed that these catalysts consisted of both $\mathrm{Cu}(100)$ terraces and steps (Fig. 6I-L). These features were not observed on either the electropolished $\mathrm{Cu}$ or $\mathrm{Cu}$ nanoparticles. ${ }^{[21]}$ For the latter catalyst, HRTEM revealed that their surfaces were smoothly gradated, possibly with many steps, but no terraces could be found. This surface was thus classified as a high indexed plane with many steps but with no terraces. Based on these observations and consistent with the work of Hori, we conclude that both $\mathrm{Cu}(100)$ terraces and steps are important in enhancing the selectivity of $\mathrm{C}_{2} \mathrm{H}_{4}$ formation. An industrially relevant feature of the $\mathrm{Cu}$ mesocrystals is their excellent activity and selectivity towards $\mathrm{C}_{2} \mathrm{H}_{4}$ production for at least six hours.

Based on these works, the selective $\mathrm{CO}_{2}$ electroreduction to $\mathrm{C}_{2} \mathrm{H}_{4}$ over rough $\mathrm{Cu}$ surfaces has been attributed to the presence of steps, edges, defects and specific crystal planes. It could be posited that a 'right' combination of these features was required for optimal $\mathrm{C}_{2} \mathrm{H}_{4}$ production. In addition to this, Kas et al. recently demonstrated that an electrode covered with $\mathrm{Cu}$ nanoparticles could yield predominantly either $\mathrm{CH}_{4}$ or $\mathrm{C}_{2} \mathrm{H}_{4}$ by changing the concentration of the electrolyte or $\mathrm{CO}_{2}$ pressure. ${ }^{[\mathrm{b}]}$ It was suggested that $\mathrm{C}_{2} \mathrm{H}_{4}$ formation is favored by a high local $\mathrm{pH}$ at the interface of the electrode, which could be actualized by lowering the concentration of the electrolyte (hence, affecting its buffer capacity). This study shows that local $\mathrm{pH}$ is an important factor that needs to be considered when performing selective $\mathrm{CO}_{2}$ electroreduction to $\mathrm{C}_{2} \mathrm{H}_{4}$.

The mechanisms for the formation of $\mathrm{CH}_{4}$ and $\mathrm{C}_{2} \mathrm{H}_{4}$ have been proposed. It is widely accepted that $\mathrm{CH}_{4}$ is formed from adsorbed $* \mathrm{CO}$ species. ${ }^{[11 \mathrm{~b}, 13,22]} * \mathrm{CO}$ is first protonated/reduced to $* \mathrm{CHO}$. This intermediate is further reduced to $* \mathrm{CH}_{3}$, and then to $\mathrm{CH}_{4}{ }^{[22 \mathrm{~b}]}$ Hori et al. suggested two routes to the formation of $\mathrm{C}_{2} \mathrm{H}_{4}{ }^{\left[{ }^{23]}\right.}$ The first is a Fischer-Tropsch like reaction: insertion of $* \mathrm{CO}$ into $* \mathrm{CH}_{2}$ to give $* \mathrm{CH}_{2} \mathrm{CO}$, which is further reduced to $\mathrm{C}_{2} \mathrm{H}_{4}$. The second is the direct dimerization of two $* \mathrm{CH}_{2}$

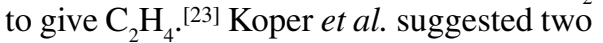
possible reaction pathways for $\mathrm{C}_{2} \mathrm{H}_{4}$ formation on $\mathrm{Cu}$ single crystal surfaces. ${ }^{[22 \mathrm{c}]}$ One pathway shares an intermediate with the formation of $\mathrm{CH}_{4}$ and occurs favorably on $\mathrm{Cu}(111)$ facets or steps. The other one takes place at $\mathrm{Cu}(100)$ facets at relatively low overpotentials. It was proposed that the dimerization of two $* \mathrm{CO}$ to give a $\mathrm{CO}$ dimer is key in this mechanism. Montoya et al. studied the $\mathrm{C}-\mathrm{C}$ coupling process in $\mathrm{CO}_{2}$ electrochemical reduction by DFT.[7] The kinetic energy barriers to $\mathrm{C}-\mathrm{C}$ coupling was found to decrease significantly with the degree of hydrogenation of $\mathrm{C}_{1}$ reactants. The more protonated the $\mathrm{C}_{1}$ species are, the more favored the dimerization would be. More experimental studies are needed to identify the pertinent reaction intermediates so as to ascertain the $\mathrm{C}-\mathrm{C}$ coupling mechanism during the formation of $\mathrm{C}_{2} \mathrm{H}_{4}$.

\section{Summary}

Extensive research has been dedicated to this field of $\mathrm{CO}_{2}$ electroreduction over the past few years. Progress has been made in both identifying electrocatalysts for selective production of formate, $\mathrm{CO}$ and hydrocarbons, and understanding the reaction mechanism. For a more efficient development of efficacious $\mathrm{CO}_{2}$ reduction catalysts, a deeper characterization of the reaction mechanism and active catalytic sites at the molecular level is needed. Correlations could then be drawn between the properties of the catalysts with the type, lifetime and quantity of transient surface intermediates and products formed during $\mathrm{CO}_{2}$ reduction. Various state of the

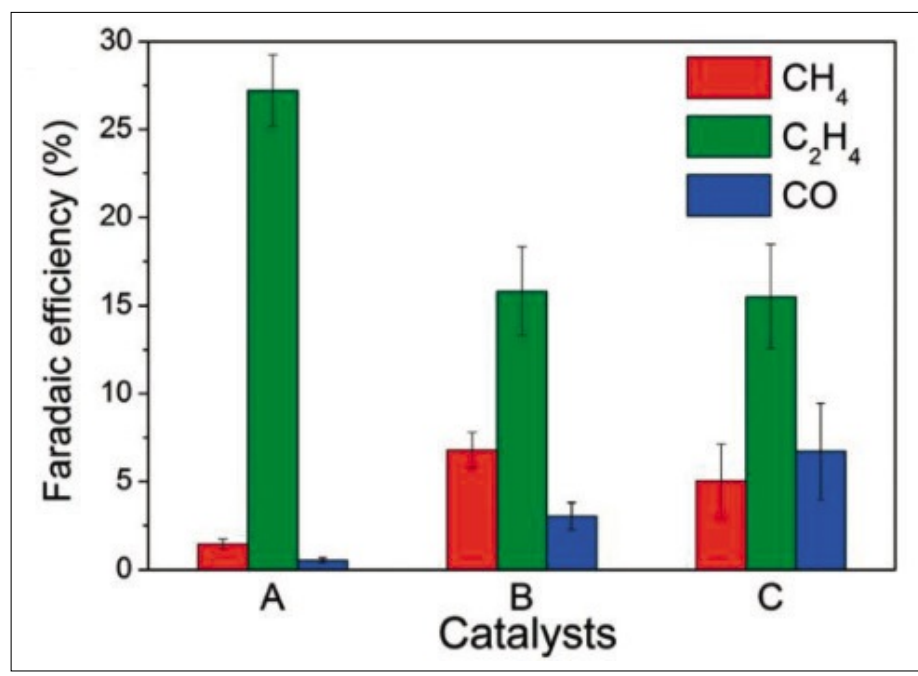

Fig. 5. Faradaic efficiencies of $\mathrm{CO}_{2}$ electroreduction products $\left(\mathrm{CH}_{4}, \mathrm{C}_{2} \mathrm{H}_{4}\right.$ and $\left.\mathrm{CO}\right)$ on catalysts: $\mathrm{A}=\mathrm{Cu}$ mesocrystals, $\mathrm{B}=\mathrm{Cu}$ nanoparticles and $\mathrm{C}=$ electropolished $\mathrm{Cu}$. Adapted with permission from ref. [21]. Copyright (c) Royal Society of Chemistry. 


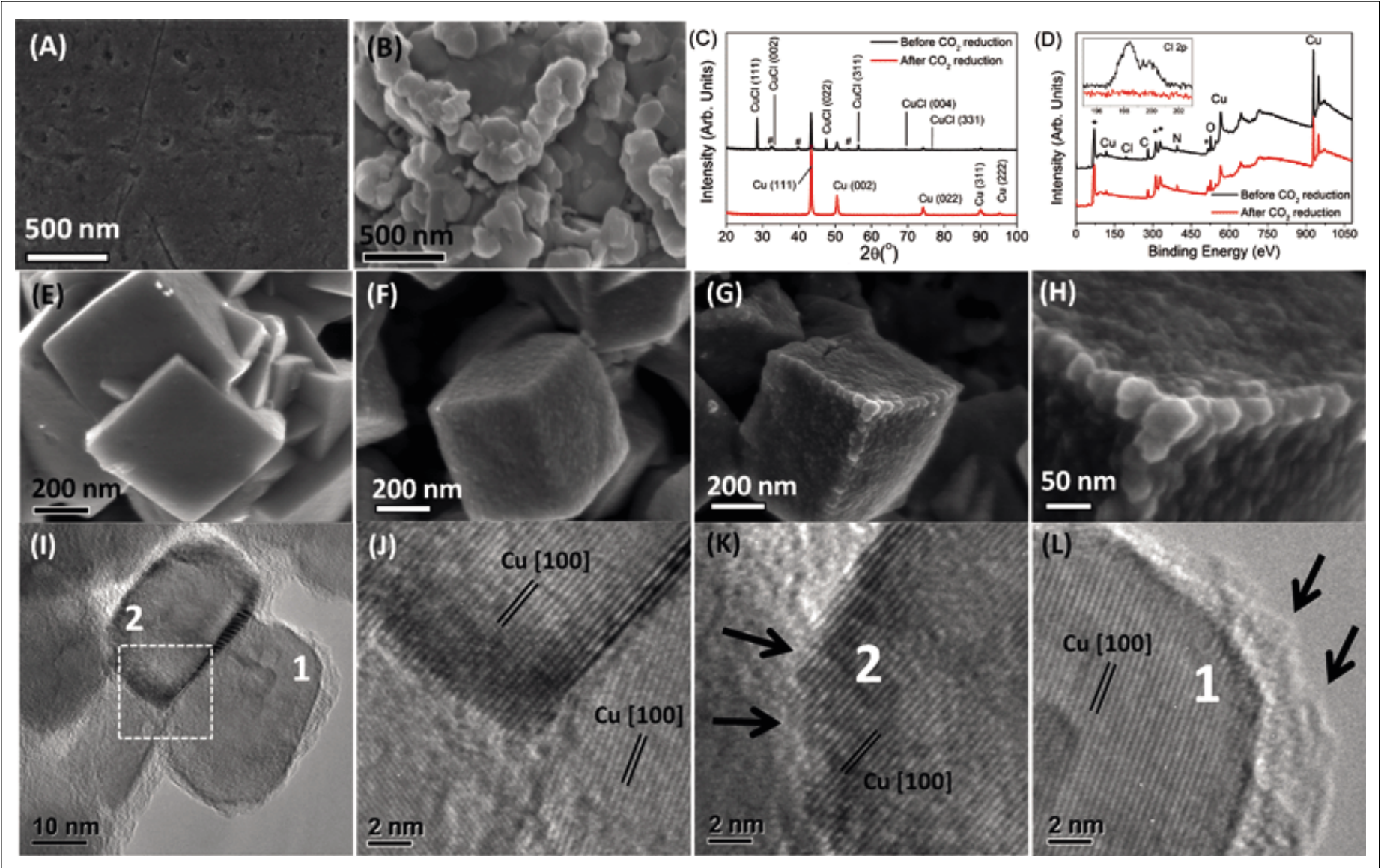

Fig. 6. SEM images of (A) polished $\mathrm{Cu}$ and (B) deposited $\mathrm{CuCl}$ layer before $\mathrm{CO}_{2}$ reduction. (C) XRD and (D) XPS data for CuCl layers before (in black) and after 4200 seconds of $\mathrm{CO}_{2}$ reduction (in red). Time-resolved ex situ SEM images showing the formation of Cu mesocrystals after (E) 10, (F) 100, and $(\mathrm{G}-\mathrm{H}) 4200$ seconds of $\mathrm{CO}_{2}$ electroreduction. (I-L) HRTEM images of Cu mesocrystals in (G-H) under increasing magnifications. Steps and edges present on the $\mathrm{Cu}$ mesocrystals are indicated by the arrows. Reprinted with permission from ref. [21]. Copyright $\odot$ Royal Society of Chemistry.

art analytical techniques such as in situ time-resolved spectroscopy and electron microscopy could be used for this purpose.

\section{Acknowledgements}

This work is supported by a start-up grant (R143-000-515-133) and an academic research fund (R-143-000-587-112) from the National University of Singapore.

Received: January 29, 2015

[1] T. Stocker, D. Qin, G. Plattner, M. Tignor, S. Allen, J. Boschung, A. Nauels, Y. Xia, B. Bex, B. Midgley, 'IPCC 2013: Climate change 2013: The Physical Science Basis. Contribution of working group I to the fifth assessment report of the intergovernmental panel on climate change', 2013

[2] D. P. Schrag, Science 2007, 315, 812.

[3] S. C. Roy, O. K. Varghese, M. Paulose, C. A. Grimes, ACS Nano 2010, 4, 1259.

[4] Y. Hori, A. Murata, R. Takahashi, J. Chem. Soc., Faraday Trans. 1 1989, 85, 2309.

[5] (a) Y. Hori, K. Kikuchi, S. Suzuki, Chem. Lett. 1985, 1695; (b) K. W. Frese, J. Electrochem. Soc 1991, 138, 3338; (c) M. Watanabe, M. Shibata, A. Kato, M. Azuma, T. Sakata, J. Electrochem. Soc. 1991, 138, 3382; (d) M. Schwartz, R. L. Cook, V. M. Kehoe, R. C. MacDuff, J. Patel, A. F. Sammells, J. Electrochem. Soc. 1993, 140, 614; (e) K. P. Kuhl, E. R. Cave, D. N. Abram, T. F. Jaramillo, Energy Environ. Sci. 2012, 5, 7050; (f) W. Tang, A. A. Peterson, A. S. Varela, Z. P. Jovanov, L. Bech, W. J. Durand, S. Dahl,
J. K. Nørskov, I. Chorkendorff, Phys. Chem. Chem. Phys. 2012, 14, 76.

[6] Y. Hori, H. Wakebe, T. Tsukamoto, O. Koga, Electrochim. Acta 1994, 39, 1833.

[7] J. H. Montoya, A. A. Peterson, J. K. Nørskov, ChemCatChem 2013, 5, 737.

[8] (a) M. Gattrell, N. Gupta, A. Co, J. Electroanal. Chem. 2006, 594, 1; (b) R. Kas, R. Kortlever, H. Yilmaz, M. T. M. Koper, G. Mul, ChemElectroChem 2014, DOI: $10.1002 /$ celc. 201402373 .

[9] (a) D. W. DeWulf, T. Jin, A. J. Bard, J. Electrochem. Soc. 1989, 136, 1686; (b) Y. Hori, H. Konishi, T. Futamura, A. Murata, O. Koga, H. Sakurai, K. Oguma, Electrochim. Acta 2005, $50,5354$.

[10] (a) S. Sen, D. Liu, G. T. R. Palmore, ACS Catal. 2014, 4, 3091; (b) H. Yano, T. Tanaka, M. Nakayama, K. Ogura, J. Electroanal. Chem. 2004, 565, 287; (c) M. Azuma, K. Hashimoto, M. Hiramoto, M. Watanabe, T. Sakata, J. Electroanal. Chem. 1989, 260 441; (d) R. Reske, H. Mistry, F. Behafarid, B. Roldan Cuenya, P. Strasser, J. Am. Chem. Soc. 2014, 136, 6978; (e) O. A. Baturina, Q. Lu, M. A. Padilla, L. Xin, W. Li, A. Serov, K. Artyushkova, P. Atanassov, F. Xu, A. Epshteyn, T. Brintlinger, M. Schuette, G. E. Collins, ACS Catal. 2014, 4, 3682

[11] (a) A. A. Peterson, F. Abild-Pedersen, F. Studt, J. Rossmeisl, J. K. Norskov, Energy Environ. Sci. 2010, 3, 1311; (b) A. A. Peterson, J. K. Nørskov, J. Phys. Chem. Lett. 2012, 3, 251.

[12] (a) Y. Hori, in 'Modern Aspects of Electrochemistry', Eds. C. Vayenas, R. White, M. Gamboa-Aldeco, Springer New York, 2008, Vol. 42; (b) Q. Lu, J. Rosen, F. Jiao, ChemCatChem 2014, 7, 38.
[13] T. Hatsukade, K. P. Kuhl, E. R. Cave, D. N. Abram, T. F. Jaramillo, Phys. Chem. Chem. Phys. 2014, 16, 13814.

[14] F. Köleli, T. Atilan, N. Palamut, A. M. Gizir, R. Aydin, C. H. Hamann, J. Appl. Electrochem. 2003, 33, 447 .

[15] J. Wu, F. G. Risalvato, S. Ma, X.-D. Zhou, J. Mat. Chem. A 2014, 2, 1647.

[16] S. Zhang, P. Kang, T. J. Meyer, J. Am. Chem. Soc. 2014, 136, 1734.

[17] R. Hinogami, S. Yotsuhashi, M. Deguchi, Y. Zenitani, H. Hashiba, Y. Yamada, ECS Electrochem. Lett. 2012, 1, H17.

[18] (a) Y. Chen, M. W. Kanan, J. Am. Chem. Soc. 2012, 134, 1986; (b) C. W. Li, M. W. Kanan, J. Am. Chem. Soc. 2012, 134, 7231; (c) Y. Chen, C. W. Li, M. W. Kanan, J. Am. Chem. Soc. 2012 134, 19969.

[19] Q. Lu, J. Rosen, Y. Zhou, G. S. Hutchings, Y. C. Kimmel, J. G. Chen, F. Jiao, Nat. Commun. 2014, 5, 3242.

[20] (a) Y. Hori, I. Takahashi, O. Koga, N. Hoshi, J. Mol. Catal. A: Chem. 2003, 199, 39; (b) Y. Hori, I. Takahashi, O. Koga, N. Hoshi, J. Phys. Chem. B 2002, 106, 15 .

[21] C. S. Chen, A. D. Handoko, J. H. Wan, L. Ma, D. Ren, B. S. Yeo, Catal. Sci. Technol. 2015, 5 , 161.

[22] (a) Y. Hori, A. Murata, Y. Yoshinami, J. Chem. Soc., Faraday Trans. 1991, 87, 125; (b) K. Schouten, Y. Kwon, C. Van der Ham, Z. Qin, M. Koper, Chem. Sci. 2011, 2, 1902; (c) K. J. P. Schouten, Z. Qin, E. P. Gallent, M. T. M. Koper, J. Am. Chem. Soc. 2012, 134, 9864.

[23] Y. Hori, R. Takahashi, Y. Yoshinami, A. Murata, J. Phys. Chem. B 1997, 101, 7075. 